Kansas State University Libraries

New Prairie Press

\title{
DESIGNED EXPERIMENTS IN THE PRESENCE OF SPATIAL CORRELATION
}

David B. Marx

Follow this and additional works at: https://newprairiepress.org/agstatconference

Part of the Agriculture Commons, and the Applied Statistics Commons

\section{(c) $($ ) $\ominus$}

This work is licensed under a Creative Commons Attribution-Noncommercial-No Derivative Works 4.0 License.

\section{Recommended Citation}

Marx, David B. (1992). "DESIGNED EXPERIMENTS IN THE PRESENCE OF SPATIAL CORRELATION,"

Conference on Applied Statistics in Agriculture. https://doi.org/10.4148/2475-7772.1398

This is brought to you for free and open access by the Conferences at New Prairie Press. It has been accepted for inclusion in Conference on Applied Statistics in Agriculture by an authorized administrator of New Prairie Press. For more information, please contact cads@k-state.edu. 


\title{
DESIGNED EXPERIMENTS IN THE PRESENCE OF SPATIAL CORRELATION David B. Marx \\ University of Nebraska-Lincoln
}

\begin{abstract}
Soil heterogeneity is generally the major cause of variation in plot yield data and the difficulty of its interpretation. If a large degree of variability is present at a test site, some method of controlling it must be found. Controlling experimental variability can be achieved either by good experimental design or by analysis procedures which account for the spatial correlation. Classical designs are only moderately equipped to adjust for spatially correlated data. More complex designs including nearest neighbor designs, Williams designs, and certain restricted Latin square designs are developed for field experimentation when spatial correlation causes classical designs to be less desirable.

The designs, both classical and nearest neighbor type designs, are analyzed using the classical statistical analysis approach and a strategy using general linear mixed models which takes into account that there is spatial correlation present. The results indicate that properly designed experiments may be analyzed either by the usual statistical techniques or more complex methods which adjust for spatial correlation. However, if no serious thought is used in constructing the design of the experiment then the usual analysis techniques are no longer valid.

Keywords: spatial variability, geostatistics, optimal designs
\end{abstract}




\section{Introduction}

Soil heterogeneity is generally the major cause of variation in plot yield data and the difficulty of its interpretation $(1,4,15)$. If a large degree of variability is present at a test site, some method of controlling it must be found. Controlling experimental variability is the major purpose of a good experimental design (18). However, adequate control of soil variability may require complex designs which may be difficult to implement, due to constraints on randomization or because of the need for knowledge which is not available, and they are often difficult to analyze. Measuring related variables and using analysis of covariance has been shown to be a good analysis technique to improve a design's efficiency $(17,18,19)$. If a plot is surrounded by neighbors who are doing well, it can be expected that it will do well also. If this plot does in fact do well, that fact does not necessarily mean that the treatment which was applied to that plot is doing well. Conversely, if a plot is surrounded by plots who are doing poorly, then the treatment applied to that plot might be considered relatively good even if the response to the treatment is inferior when viewing that plot in isolation.

Nearest neighbor (NN) analysis was first introduced by Papadakis (15) and then reviewed by Bartlett (3) in a more mathematically critical paper. NN allows for the recovery of information from replicated field experiments with large blocks (2). This is especially useful in cultivar trials or other experiments where large numbers of treatments or cultivars are used. Generally, the procedure calls for the development of a covariate for a particular plot by averaging the yields of surrounding plots.

Researchers can also adjust the analysis of spatially dependent variables through the theory of regionalized variables developed by Georges Matheron (11, 12). The application of Matheron's theory to problems originating in mining and geology led to the more popular name of geostatistics (7). The quantifying of the spatial correlation is done by constructing a semivariogram which describes the spatial relationship through the parameters of nugget, range, and sill (5). Using the geostatistical representation of the spatial data in conjunction with general mixed model theory in statistics allows for a more general solution of the spatial analysis problem $(13,20)$.

Besides yield data many variables of interest to crop and soil scientists are spatially dependent $(6,21)$. These include soil nutrients, soil physical properties, plant nutrients, and plant physical properties $(23,24)$. In most courses on design of experiments offered to graduate students in agriculture, the emphasis is on classical experimental design and the resulting analyses. These courses typically create the impression that the designs should always be balanced and randomized and that blocking is usually effective. However, in agricultural field experimentation 
often there is a correlation between adjacent plots. This spatial correlation violates the assumption of independent observations which is necessary for ordinary least squares analyses to have valid statistical tests of hypotheses, which is the basis of classical statistical analysis.

It is necessary to account for this spatial correlation in the data when analyzing data from highly correlated plots. There are several ways to modify the analysis so that the spatial correlation can be taken into account. We will begin with the classical method of accounting for spatial correlation and then develop some more sophisticated methods of analysis which are now possible with the use of a personal computer.

\section{Blocking and Classical Experimental Designs}

Classical experimental designs are based on the principle of blocking. Blocking involves arranging homogeneous experimental units (in our case plots) into groups so that the variability between experimental units within a group (block) is less than the variability between experimental units of differing blocks. This allows more precise comparison of treatments by eliminating large differences between experimental units in different blocks. Information from blocked experiments is predominantly based on the comparisons that can be made between treatment observations within the same block. Although not with the same degree of efficiency, comparisons can also be made between treatments not in the same block.

In field plot designs, blocking usually proceeds by grouping soil types together, blocking by aspect or elevation, blocking by proximity to a river or stream, or simply blocking by taking groups of adjacent plots and assuming that plots in close proximity to each other are more similar that plots which are farther apart.

The most commonly used experimental design is the randomized complete block ( $\mathrm{RCB}$ ). A randomized complete block design is one in which each treatment or treatment combination (in the case of factorials) appears exactly once within each block. We choose blocks so that they represent relatively homogeneous sources of variation before the treatment is applied. Common examples of blocks are fields, years, littermates, batches of chemicals, or environmental conditions. When blocking is to be done in two directions (or to account for heterogeneity in two uncontrolled variables), the design can be laid out as a Latin Square.

The difficulty with either of these classical techniques is that often the number of treatments is large requiring many experimental units to be similar. This is seldom the case and thus the heterogeneity between experimental units within a block is great when the block is large. Balanced incomplete block designs (BIBD) help to alleviate this problem. Here blocks have fewer units than there are treatments. Thus not all treatments can be contained within one block. The advantage is that by limiting the number of units per block, 
the units within each block can be quite similar. The disadvantage is that not all treatments appear within a block so that comparisons between treatments are made with less efficiency than would be the case if homogeneous complete blocks were possible. If the variability within a block is reduced enough by restricting its size, this disadvantage is offset. If not then $a n$ RCB is preferable. In general, the larger the number of treatments, the more likely an incomplete block design will be more efficient than an RCB design.

A second difficulty with the RCB is that in the presence of spatial correlation, not all treatment differences are measured with equal precision. For example, if a Randomized Complete Block Design is to be run with four treatments and four replications, one such design could be derived through the use of a random number table or have been obtained through a design package (such as SAS) on computer. Figure 1 represents such a design. If the treatment placements are taken into account then the comparisons of treatments are made at different average distances. These are given in Table 1. In this example the average treatment comparison (over all treatment pairs) distance is $5 / 3=1.667$. Our average distances for particular treatment comparisons, in this case, range from 1.00 ( $B$ vs D) to 2.25 (A vs D). Since when using a usual analysis of variance all treatment comparisons are judged against the same standard error, we will be using too large an error term for the B Vs D comparison and too small an error term for the A vs D comparison. This is true only if the spatial correlation extends the length of each block.

An extension to the Latin square which is not as well known is the Youden square or incomplete Latin square. In this design the rows are complete blocks and the columns are incomplete blocks. For example a Youden square for seven treatments with three replications is given in Figure 2 . Note that each row forms a complete block in that each treatment appears exactly once. The columns form incomplete blocks which are balanced since each treatment pair appears within a column exactly once. Thus the columns form a BIBD.

Pearce (16) has extended the concept of several blocking schemes to "row and column" designs. Blocks can generally be made of any size but the restrictions on the field size and shape may determine the number of plots in each row and column. In this case the number of plots in each row or column may be more or less than the number of treatments. Mead (14) suggests that in constructing row and column designs the allocation of treatments to rows and columns may be considered separately. For each blocking system the distribution of treatments should be made to be orthogonal if possible and if not they should be balanced. If even balance is not possible, then the joint occurrences in blocks should be made as nearly equal for all treatment pairs as possible. Where two treatments have an unusually high occurrence for one blocking scheme, say rows, then the two treatments should be arranged so that they have an unusually low occurrence for the other blocking scheme, say columns. When the row and column 
apportionments are complete the joint allocation is constructed to be compatible with the separate apportionments.

Thus although spatial correlation is present to some degree in all field experiments, whether on a micro or macro scale, it is important to recognize this correlation and try to accommodate for it by

1. Adjusting the design of the experiment

2. Modifying the analysis of the resulting data

3. Some combination of both 1 and 2 .

\section{Designs which Control for spatial Variability}

Some other designs which help control for spatial correlation include nearest neighbor balanced designs and Williams designs $(8,9,22)$. Using the idea of determining the average distance between treatments for each treatment pair as suggested earlier, different designs can be compared. Figures 3 through 7 show some incomplete block, Williams, and nearest neighbor designs. Although these designs are for different numbers of treatments and replications, we would normally choose a design which had, as close as possible, the same average distance between all pairs of treatments. In practice this is quite hard to do, especially if the number of treatments is large and the number of replications is to be kept relatively small. The question then becomes, how do we determine which designs are "good" or which of several competing designs is the "best"?

There are several criteria which are used in classical statistics. These include:

a) standard error of the mean

$$
\begin{aligned}
& E_{e}(R C B) / r \quad \text { where } \\
& E_{e}(R C B)=\text { mean square error for } R C B
\end{aligned}
$$

b) efficiency of a design

$$
E_{e}(C R D)=\left(n_{b} E_{b}+\left(n_{t}+n_{e}\right) E_{e}\right) /\left(n_{b}+n_{t}+n_{e}\right)
$$

where $E_{e}(C R D)=$ mean square error for a CRD based upon a $R C B$ analysis and from the RCB $n_{b}, n_{t}$, and $n_{e}$ are the degrees of freedom for blocks, treatments and error respectively with mean squares for blocks and error being $E_{b}$ and $E_{e}$ respectively.

$E(R C B$ to $C R D)=\frac{E_{e}(C R D)\left(n_{e(R C B)}+1\right)\left(n_{e(C R D)}+3\right)}{E_{e}(R C B)\left(n_{e(C R D)}+1\right)\left(n_{e(R C B)}+3\right)}$

where $n_{e(C R D)}$ and $n_{e(R C B)}$ are the degrees of freedom for error associated with the CRD and RCB, respectively. 
c) standard error of the difference between two treatments $\checkmark\left[2 E_{e}(R C B) / n\right]$

d) if the data are unbalanced use the average of the standard error of the differences between the means

$$
\text { average } \quad V\left[\left(1 / n_{i}+1 / n_{j}\right) E_{e}(R C B)\right]
$$

Although these are all valid measures of good design the calculation of the standard error of the differences between the means is tedious when spatial correlation is present. In addition, some assumption about the spatial variability must be made in order to obtain these standard errors accurately. The usual formulas for efficiency are valid for independent observations, but obtaining the mean square errors in the presence of spatial variability is difficult.

Another method of comparing designs is to use one of the optimality criteria. For independent observations A-OPTIMALITY is defined as:

$A$-OPTIMALITY $=\Sigma\left(1 / \lambda_{i}\right)$, where $\lambda_{i}=i^{\text {th }}$ eigenvalue of $X^{\prime} X$ and $\mathrm{X}$ is the design matrix. A-OPTIMALITY minimizes:

i) the average variance of the treatment effects.

ii) the average variance of an estimated difference in treatment effects.

iii) the expected value of the treatment sum of squares when there are no treatment differences.

A second optimality criteria is also sometimes used. D-OPTIMALITY is defined for independent observations as:

D-OPTIMALITY $=\Pi \lambda_{i}$. ellipsoid.

i) is proportional to the volume of the confidence

ii) minimizes the maximum variance of predicted responses (generally in regression).

Thus D-optimal designs correspond to a design matrix, $\mathrm{x}$, such that $\left|X^{\prime} X\right|$ (or $\pi \lambda_{i}$ ) is maximal.

other criteria also include:

i) maximum standard error of treatment differences.

ii) minimum standard error of treatment differences.

iii) variance of standard errors of treatment

differences.

If spatial correlation is present, how do we find an "optimal" design? How do we define spatial correlation? Martin (10) has proposed an extension to both the A-OPTIMALITY and D-OPTIMALITY criteria for spatially correlated data. His criteria simply use the $\left(X^{\prime} V^{-1} X\right)$ matrix instead of the $\left(X^{\prime} X\right)$ matrix. For example, if one assumes a spatial structure which produces a spherical semivariogram as seen in figure 8, then the generalized optimality criteria can be defined by: 
A-OPTIMALITY $=\Sigma\left(1 / \lambda_{i}\right)$ and D-OPTIMALITY $=\Pi \lambda_{i}$, where $\lambda_{i}=$ $i^{\text {th }}$ eigenvalue of $\left(X^{\prime} V^{-1} X\right), X$ is the design matrix, and $V^{-1}$ is the inverse of the covariance structure of a spatially correlated design. $\mathrm{V}=\left[\mathrm{v}_{\mathrm{ij}}\right]$ where $\left[\mathrm{v}_{\mathrm{ij}}\right]=\mathrm{C}\{1-1.5 * \mathrm{~h} / \mathrm{r}+$ $\left..5 * h^{3} / r^{3}\right\}, h$ is the distance between observation $i$ and observation $j$, and $r$ is the range of the spherical semivariogram. Here the covariance matrix for the stochastic error term of the linear model, $V$, is defined for a spherical spatial structure but any other spatial structure could be incorporated into $\mathrm{V}$ just as easily.

Note that in almost all spatial structures the correlation tends to decrease with distance. Since most structures are fairly linear at smaller distances the choice of a structural model is important but not as critical as recognizing that spatial structure exists.

Standard errors of all the treatment differences are calculated by:

$\mathrm{k}^{\prime} *\left(\mathrm{X}^{\prime} \mathrm{V}^{-1} \mathrm{X}\right)^{-1} * \mathrm{k}$ where $\mathrm{k}=(1,0,0, \ldots,-1,0, \ldots)^{\prime}$,

for all possible k's. These standard errors can then be calculated and compared for designs when spatial structure is present.

\section{Simulation Procedure}

Now that we have optimality criteria for data with spatial variability, a simple simulation study for Latin square designs in the presence of a spherical semivariogram spatial structure was run. Unlike classical statistical designs not all Latin squares are created equal. For $5 \times 5$ Latin squares there are "good" designs and "poor" designs. For the first part of the simulation 2,000 randomized $5 \mathrm{X} 5$ Latin squares were observed to determine which were "good" designs and which were "poor". The average scores for different criteria are given in table 2 for both a range of 2.5 and a range of 10.0. In all cases there was no nugget effect and the sill was 100 for the spherical model. From the individual results a "good" design was selected as well as a "poor" design based upon the A-OPTIMALITY criteria. Although A-OPTIMALITY is used since it is intuitively more appealing, both criteria gave in this simulation example the same result. These designs are the knight's move design and the diagonal design respectively as given in figure 9 .

These designs were then compared with 100 simulations of data with the following structure for the spatial correlation:

1. spherical structure

nugget $=0.0$

range $=2.5$ or 10.0

sill $=100.0$

2. add treatment effects to spatial "floor"

treatment means $\mathrm{A}=\mathrm{B}=\mathrm{C}=0.00$

$$
\mathrm{D}=10.0, \mathrm{E}=20.0 \text {, }
$$


square)

$$
F=30.0 \text { (used only for the } 6 \times 6
$$

The simulation first developed experimental units which were spatially correlated with the spherical structure (call the "floor" above) and then the treatment effects were added (with no additional error component) to these experimental units according to the appropriate design.

The simulations were run for:

1. two ranges $(2.5,10.0)$
2. two sizes of Latin squares ( $5 \times 5,6 \times 6)$
3. two squares of each size ("good", "poor")
4. 100 simulations for each of the 8 cells

\section{simulation Results}

The results are given in table 3. Note that the diagonal Latin square is very poor in comparison to the knight's move. In addition, based upon the means from table 2, there seem to be a number of fairly good Latin square designs although the knight's move is the best under the spatial correlation structure proposed.

Table 4 shows a comparison between treatments $A$ and $B$ as well as $A$ and $C$. These comparisons were chosen since they have the largest and smallest standard errors of differences between treatment means. Note that for the knight's move design the difference between the standard errors is very small. However, for the diagonal design the difference between the standard errors is over $25 \%$. Thus the knight's move design also does a good job of estimating treatment differences with good precision for all pairs of treatments. Table 5 gives the results of the simulation when the data (including both "good" and "poor" designs averaged) were analyzed using a mixed model program assuming a spherical correlation structure and also analyzed using the classical Latin square analysis. These results indicate that the classical analysis will underestimate the error variance in the presence of spatial correlation and the larger the range the greater the bias in the estimation.

For the $6 \times 6$ Latin square no knight's move design exists but the best design found along with the worst (again a diagonal design) is given in figure 10. The simulation results for the 6 X 6 Latin squares were essentially the same as for the $5 \times 5$ Latin square and thus are omitted here.

Lastly, one more simulation was done to compare a completely randomized design and four 5 X 5 Latin square designs in the presence of spatial variability. For the $5 \times 5$ Latin squares a pair of "opposite" diagonal squares was replicated for a total of four squares. The designs are given 
in figure 11 and you will note that by using these opposing diagonal squares that the average distance between treatment pairs is about the same for all treatment pairs. Thus, diagonal squares may be good designs for dealing with spatial variability, but only when used in pairs which when viewed as an overall design average out the distance between treatment pairs.

Table 6 shows the results of the simulation of the designs of figure 11. Note that when the CRD is analyzed the analysis accounting for the spatial structure correctly assigns differing standard errors of treatment differences for varying pairs of treatments. The classical analysis fails to do this and in fact gives inflated standard errors. However, when an appropriate design for spatial structure is used the analysis is not as important. As can be seen the classical analysis and the generalized least squares analysis give approximately the same results for the four Latin squares.

Although the simulations used here assumed a point to point semivariogram and actually, since plot designs have been discussed, the covariance values in the optimality criteria or in the generalized linear model structure are only approximations. The actual covariance values needed for both the calculation of the optimality criteria and the generalized least squares analyses should be the covariance function which is averaged between all points from one plot to the next. This involves a four fold integral of the covariance function. often the most effective solution is to choose sixteen gridded points in each plot and average the 256 pairs of points for the average covariance as shown in figure 12. However, the point to point covariance approximation used here should be fairly close to the exact values for the semivariogram constructed by using areas.

\section{Conclusions}

If spatial correlation is not present, randomize Latin squares in the usual manner and conduct the usual analysis. Usual blocking techniques will be helpful in eliminating excess variability among experimental units. However, if spatial correlation is present, then use a "good" design or use proper analysis techniques or use a "good" design and use proper analysis techniques. 


\section{References}

1. Baker, R. J. and R. I. H. McKenzie. 1967. Use of control plots in yield trails. Crop Sci. 7:335-337.

2. Bartlett, M. S. 1938. The approximate recovery of information from replicated field experiments with large blocks. J. Agric.Sci. 38:418-427.

3. Bartlett, M. S. 1978. Nearest neighbor models in the analysis of field experiments. J. Royal statistical Society, B, $40: 147-174$.

4. Bryan, A. A. 1933. Factors affecting experimental error in field plot test with corn. Iowa Agric. Exp. Stn. Res. Bul. 163:244-280

5. Clark, I. Practical Geostatistics. 1979. Applied Science Publishers, Essex, England.

6. Gajem, Y. M., A. W. Warrick and D. E. Myers. 1981. spatial dependence of physical properties of a typic torrifluvent soil. Soil Sci. Soc. Amer. J. 46:709-715.

7. Journel, A. J. and C. Huijbregts. 1978. Mining Geostatistics. Academic Press, London, England.

8. Kunert, J. 1985. Optimal repeated measurements designs for correlated observations and analysis by weighted least squares. Biometrika. $72,2,375-389$.

9. Kunert, J., and Martin, R. J. 1987. Some results on optimal design under a first-order autoregression and on finite Williams type II designs. Comm. Stat. - Theory Meth. $16(7), 1901-1922$.

10. Martin, R. J. 1986. On the design of experiments under spatial correlation. Biometrika. $73,2,247-277$.

11. Matheron, G. 1962-1963. Traitè de Gèostatistique Appliquèe, Vols 1 and 2, Technip, Paris.

12. Matheron, G. 1965. Les Variables Règionalisèes et leur Estimation, Masson, Paris.

13. McLean, R.A., Sanders, W.L., and Stroup, W.W. 1991. A unified approach to mixed linear models. American statistician. 45:54-63.

14. Mead, Roger, The design of experiments, Cambridge University Press, 1988, pp. 620.

15. Papadakis, J. S. 1937. Bull. Inst. Amél. Plantes à 
Salonique, No. 23 .

16. Pearce, S. C., Row-and-column Designs, Applied Statistics, 1975, 24, No. 1, p. $60-74$.

17. Pearce, S. C. 1978. The control of environmental variation in some West Indian maize experiments. Trop. Agric. (Trinidad), 55:97-106.

18. Snedecor, G. W. 1946. Statistical methods. 4th Ed. Iowa State College Press, Ames, Iowa.

19. Steele, R. D. G., and J. H. Torrie. 1960. Principles and procedures of statistics. McGraw Hill Book Co., Inc., New York.

20. Stroup, W. W., R. A. McLean, and W. L. Saunders. 1989. Part I in Applications of Mixed Models in Agriculture and Related Disciplines, Southern Cooperative Series Bulletin No. 343. pp 1-56. Louisiana Agricultural Experiment station. Baton Rouge, Louisiana.

21. Warrick, A. W., and D. R. Nielsen. 1980. Spatial variability of soil physical properties in the field. In Hillel, D. Applications of soil physics. Academic Press, New York.

22. Williams, E. R. 1986. Row and column designs with contiguous replicates. Austral. J. Stat. 28(2), 154-163.

23. Yost, R. S., G. Uehara, and R. L. Fox. 1982a. Geostatistical analysis of soil chemical properties of large land areas. I. S e mivariogram s. So 1 Sci. Soc. Am. J. 46:1028-1032.

24. Yost, R. S., G. Uehara, and R. L. Fox. 1982b. Geostatistical analysis of soil chemical properties of large land areas. II. Kriging. Soil Sci. Soc. Am. J. 46:1033-1037. 
Figure 1.

Example of RCB with distances between treatments indicated.
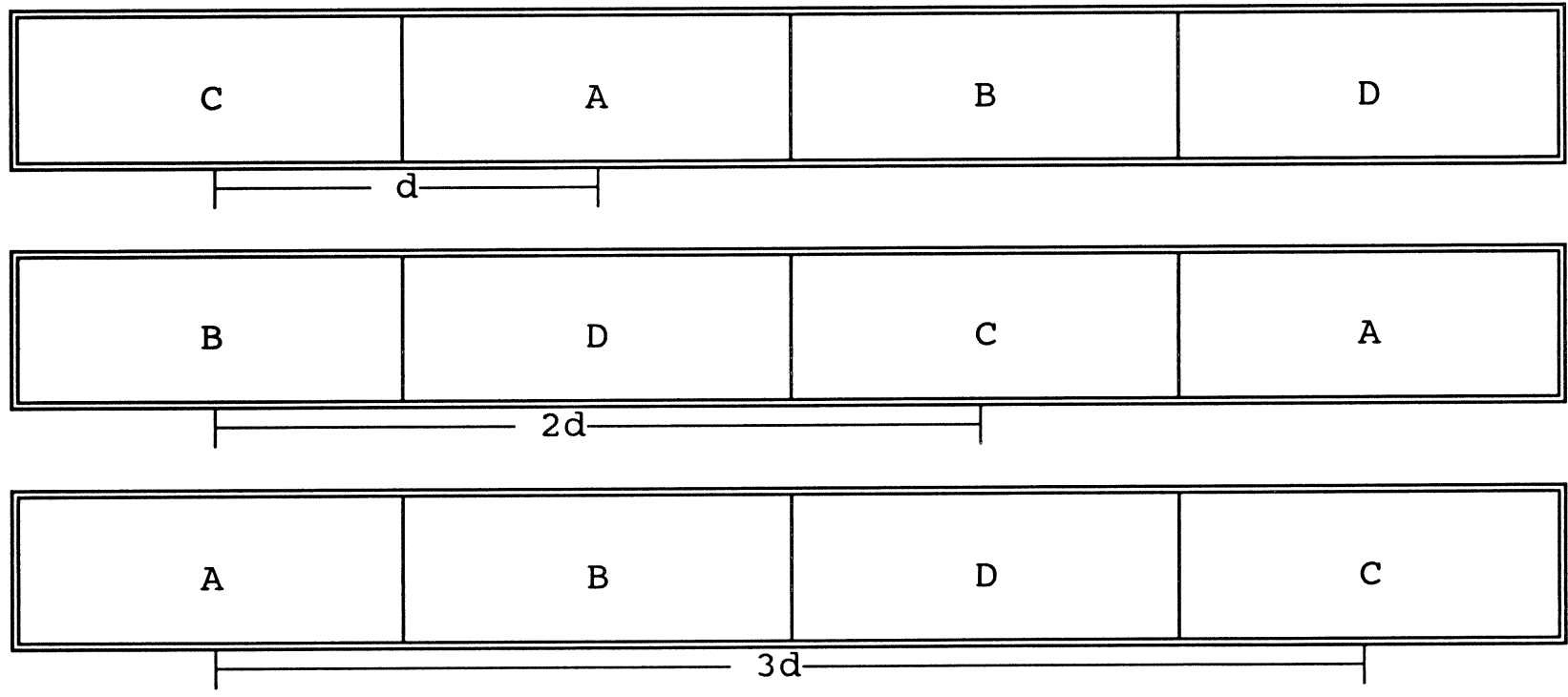

\begin{tabular}{||c|c|c|c|}
\hline $\mathrm{D}$ & $\mathrm{B}$ & $\mathrm{C}$ & $\mathrm{A}$ \\
\hline
\end{tabular}

Table 1 .

Distances between treatments.

\begin{tabular}{||c|c|c|c|c|c||}
\hline Comparison & Block 1 & Block 2 & Block 3 & Block 4 & Average \\
\hline \hline A vs. B & 1 & 3 & 1 & 2 & $7 / 4$ \\
\hline A vs. C & 1 & 1 & 3 & 1 & $6 / 4$ \\
\hline A vs. D & 2 & 2 & 2 & 3 & $9 / 4$ \\
\hline B vs. C & 2 & 2 & 2 & 1 & $7 / 4$ \\
\hline B vs. D & 1 & 1 & 1 & 1 & $4 / 4$ \\
\hline C vs. D & 3 & 1 & 1 & 2 & $7 / 4$ \\
\hline \hline Average & $5 / 3$ & $5 / 3$ & $5 / 3$ & $5 / 3$ & $5 / 3$ \\
\hline
\end{tabular}


Figure 2 .

Youden square for seven treatments

with three replications

\begin{tabular}{||c|c|c|c|c|c|c||}
\hline A & B & C & D & E & F & G \\
\hline G & A & B & C & D & E & F \\
\hline C & D & E & F & G & A & B \\
\hline
\end{tabular}

Figure 3.

Incomplete Block Design

with four treatments

and two plots per block

$\begin{array}{lllll}\text { Rep I } & \text { A } & \text { B } & \text { C } & \text { D }\end{array}$

$\begin{array}{lllll}\text { Rep II A C } & \text { B }\end{array}$

Rep III A D B C

Note that within block comparisons are made with treatments all being one plot away from each other.

Figure 4 .

Incomplete Block Design

with four treatments

and three plots per block
A $\quad$ B $\quad$ D
D $\quad$ B $\quad$ C
B $\quad$ C $A$
A $\quad$ D $\quad$ C

In this particular randomization the average difference between treatments is either 1.0 or 1.5 plot units.

Figure 5 . 


$$
\begin{aligned}
& \text { Williams Design } \\
& \text { with three treatments }
\end{aligned}
$$

$\begin{array}{lll}\text { C } & \text { A } & \text { B } \\ \text { A } & \text { B } & \text { C } \\ \text { B } & \text { C } & \text { A }\end{array}$

Note that this design is balanced for nearest neighbors in both rows and columns in that all treatment comparisons are an average of $4 / 3$ plot units apart.

\title{
Figure 6 .
}

\begin{abstract}
Balanced Nearest Neighbor Design (4 treatments) average distance apart is $5 / 3$ plot units
\end{abstract}

$\begin{array}{llll}\text { D } & \text { A } & \text { B } & \text { C } \\ \text { A } & \text { B } & \text { C } & \text { D } \\ \text { C } & \text { D } & \text { A } & \text { B } \\ \text { B } & \text { C } & \text { D } & \text { A } \\ \text { D } & \text { C } & \text { A } & \text { B } \\ \text { C } & \text { A } & \text { B } & \text { D } \\ \text { B } & \text { D } & \text { C } & \text { A } \\ \text { A } & \text { B } & \text { D } & \text { C } \\ & & & \\ \text { D } & \text { B } & \text { C } & \text { A } \\ \text { B } & \text { C } & \text { A } & \text { D } \\ \text { A } & \text { D } & \text { B } & \text { C } \\ \text { C } & \text { A } & \text { D } & \text { B }\end{array}$




$$
\text { Figure } 7 \text {. }
$$

Balanced Design with 5 treatments

$\begin{array}{lllll}\text { E } & \text { B } & \text { C } & \text { A } & \text { D } \\ \text { D } & \text { E } & \text { B } & \text { C } & \text { A } \\ \text { A } & \text { D } & \text { E } & \text { B } & \text { C } \\ \text { C } & \text { A } & \text { D } & \text { E } & \text { B } \\ \text { B } & \text { C } & \text { A } & \text { D } & \text { E } \\ & & & & \\ \text { E } & \text { C } & \text { D } & \text { B } & \text { A } \\ \text { A } & \text { E } & \text { C } & \text { D } & \text { B } \\ \text { B } & \text { A } & \text { E } & \text { C } & \text { D } \\ \text { D } & \text { B } & \text { A } & \text { E } & \text { C } \\ \text { C } & \text { D } & \text { B } & \text { A } & \text { E }\end{array}$

Note that this design is balanced for nearest neighbors in both rows and columns in that all treatment comparisons are an average of $6 / 3$ plot units apart. 
Figure 8

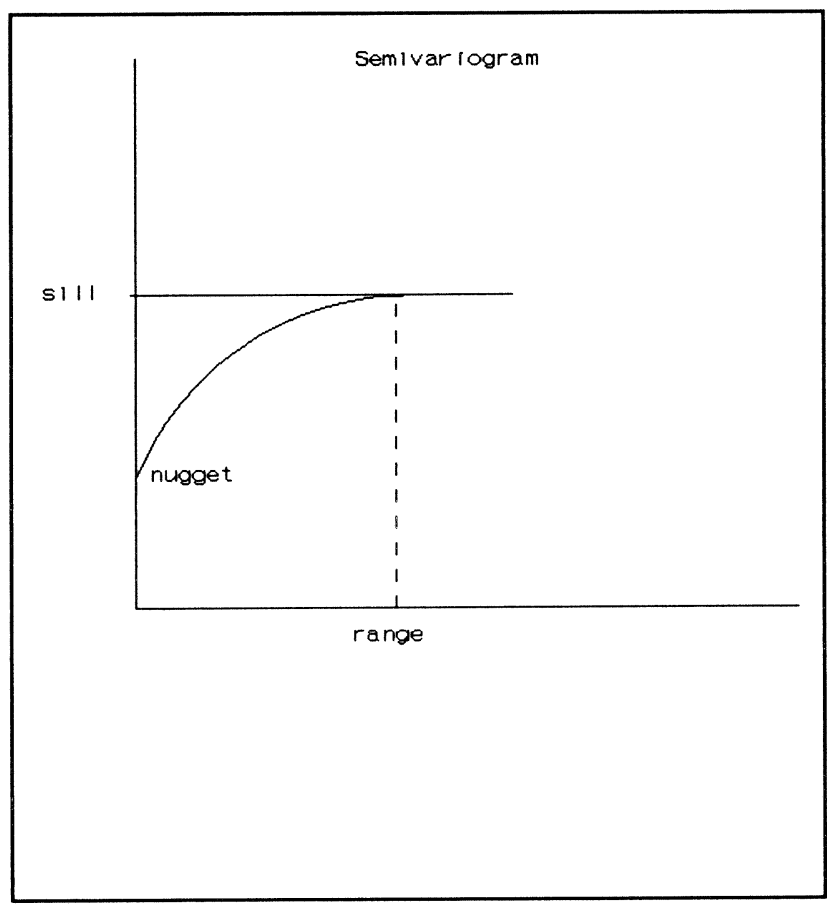

randomizations)

Table 2 .

$5 \times 5$ Latin squares

(averages of 2,000

10.0

D-OPTIMALITY

A-OPTIMALITY

average std error of diff

variance of std errors of diff

minimum std error of difference

maximum std error of difference

$$
\text { range }=2.5 \quad \text { range }=
$$

27,467

.952

.185

.000510

.156

.214
$1,869,330$

2.621

.044

.000014

.040

.048 
Figure 9.

$5 \times 5$ Latin squares

KNIGHTS MOVE

DIAGONAL

$\begin{array}{llllllllll}\text { A } & \text { B } & \text { C } & \text { D } & \text { E } & \text { A } & \text { B } & \text { C } & \text { D } & \text { E } \\ \text { C } & \text { D } & \text { E } & \text { A } & \text { B } & \text { B } & \text { C } & \text { D } & \text { E } & \text { A } \\ \text { E } & \text { A } & \text { B } & \text { C } & \text { D } & \text { C } & \text { D } & \text { E } & \text { A } & \text { B } \\ \text { B } & \text { C } & \text { D } & \text { E } & \text { A } & \text { D } & \text { E } & \text { A } & \text { B } & \text { C } \\ \text { D } & \text { E } & \text { A } & \text { B } & \text { C } & \text { E } & \text { A } & \text { B } & \text { C } & \text { D }\end{array}$

POOR

Table 3 .

(results of 100 simulations for each column)

$5 \times 5$ Latin squares

$$
\begin{array}{ccc}
\text { range } & =2.5 & \text { range }
\end{array}=10.0
$$

$\begin{array}{llll}\begin{array}{l}\text { D-OPTIMALITY } \\ 965,847\end{array} & 41,600 & 8,990 & 2,338,735 \\ \begin{array}{l}\text { A-OPTIMALITY } \\ \begin{array}{l}2.655 \\ \text { Average std error }\end{array}\end{array} & .903 & 1.164 & 2.612 \\ \begin{array}{l}.058 \\ \text { Variance of std error }\end{array} & .000025 & .006478 & .041 \\ \begin{array}{l}\text { Minimum std error } \\ \text {.044 }\end{array} & .159 & .210 & .000000 \\ \begin{array}{l}\text { Maximum std error } \\ .072\end{array} & .162 & .372 & .040 \\ \end{array}$

10.0

range $=2.5$

GOOD POOR

4.314

average std error

3.257
Table 4.

$5 \times 5$ Latin squares

means of 100 simulations

range $=$

GOOD

2.495 


$\begin{array}{llll}\begin{array}{l}\text { minimum std error } \\ 2.846\end{array} & 4.293 & 4.306 & 2.472 \\ \begin{array}{l}\text { maximum std error } \\ 3.673\end{array} & 4.336 & 5.580 & 2.512 \\ \text { std error (A vs B) } & 4.320 & 4.356 & 2.494 \\ 2.919 & & & \\ \text { std error (A vs C) } & 4.311 & 5.469 & 2.475 \\ 3.610 & & & \end{array}$


(range)

Table 5 .

\begin{tabular}{|c|c|c|c|c|}
\hline \multirow{2}{*}{ (range) } & GL: & $\begin{array}{r}5 x \\
\text { (range) }\end{array}$ & $\begin{array}{l}\text { square } \\
\text { Cla }\end{array}$ & 1 LS \\
\hline & 2.5 & 10.0 & 2.5 & 10.0 \\
\hline estimate of $\sigma^{2}$ & 104.4 & 91.3 & 66.4 & 16.2 \\
\hline estimate of range & 2.599 & 4.292 & --- & --- \\
\hline
\end{tabular}

Figure 10.

$6 \times 6$ Latin squares

NO TREATMENT A NEIGHBOR

DIAGONAL

OF ITSELF (no knights

move exists)

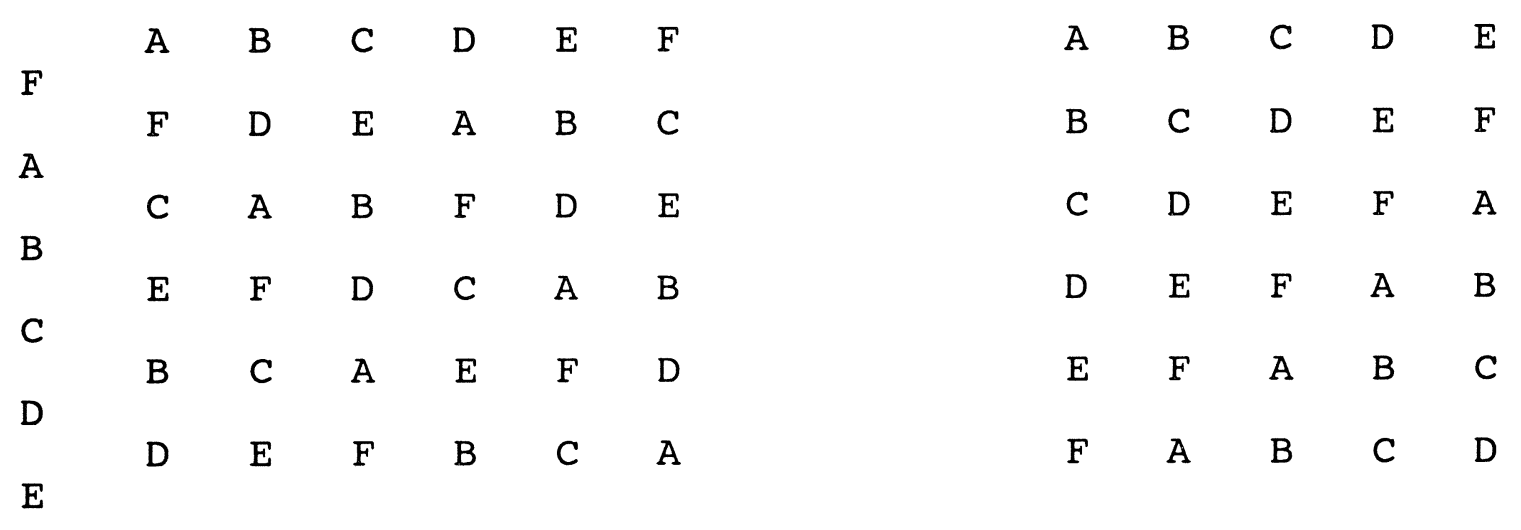


Figure 11.

Completely Randomized Design

$\begin{array}{llllllllll}\text { B } & \text { B } & \text { C } & \text { D } & \text { A } & \text { C } & \text { A } & \text { C } & \text { B } & \text { B } \\ \text { E } & \text { A } & \text { B } & \text { E } & \text { A } & \text { B } & \text { D } & \text { A } & \text { A } & \text { B } \\ \text { C } & \text { D } & \text { B } & \text { B } & \text { C } & \text { C } & \text { D } & \text { D } & \text { C } & \text { E } \\ \text { C } & \text { A } & \text { D } & \text { D } & \text { B } & \text { D } & \text { A } & \text { D } & \text { A } & \text { D } \\ \text { B } & \text { E } & \text { E } & \text { A } & \text { D } & \text { E } & \text { E } & \text { C } & \text { E } & \text { A } \\ & & & & & & & & & \\ \text { E } & \text { C } & \text { B } & \text { E } & \text { C } & \text { C } & \text { E } & \text { A } & \text { E } & \text { A } \\ \text { C } & \text { E } & \text { D } & \text { B } & \text { A } & \text { B } & \text { B } & \text { D } & \text { D } & \text { E } \\ \text { A } & \text { E } & \text { A } & \text { D } & \text { C } & \text { B } & \text { D } & \text { E } & \text { A } & \text { E } \\ \text { A } & \text { E } & \text { C } & \text { B } & \text { A } & \text { D } & \text { E } & \text { A } & \text { D } & \text { C } \\ \text { D } & \text { C } & \text { C } & \text { B } & \text { D } & \text { C } & \text { B } & \text { B } & \text { E } & \text { C }\end{array}$

Four Diagonal Latin Square Designs

$\begin{array}{llllllllll}\text { E } & \text { B } & \text { C } & \text { A } & \text { D } & \text { E } & \text { C } & \text { D } & \text { B } & \text { A } \\ \text { D } & \text { E } & \text { B } & \text { C } & \text { A } & \text { A } & \text { E } & \text { C } & \text { D } & \text { B } \\ \text { A } & \text { D } & \text { E } & \text { B } & \text { C } & \text { B } & \text { A } & \text { E } & \text { C } & \text { D } \\ \text { C } & \text { A } & \text { D } & \text { E } & \text { B } & \text { D } & \text { B } & \text { A } & \text { E } & \text { C } \\ \text { B } & \text { C } & \text { A } & \text { D } & \text { E } & \text { C } & \text { D } & \text { B } & \text { A } & \text { E } \\ & & & & & & & & & \\ \text { E } & \text { C } & \text { D } & \text { B } & \text { A } & \text { E } & \text { B } & \text { C } & \text { A } & \text { D } \\ \text { A } & \text { E } & \text { C } & \text { D } & \text { B } & \text { D } & \text { E } & \text { B } & \text { C } & \text { A } \\ \text { B } & \text { A } & \text { E } & \text { C } & \text { D } & \text { A } & \text { D } & \text { E } & \text { B } & \text { C } \\ \text { D } & \text { B } & \text { A } & \text { E } & \text { C } & \text { C } & \text { A } & \text { D } & \text { E } & \text { B } \\ \text { C } & \text { D } & \text { B } & \text { A } & \text { E } & \text { B } & \text { C } & \text { A } & \text { D } & \text { E }\end{array}$

Table 6 .

Completely Randomized Design

Treatment

Comparison
A D
.189
.370
B $E$
.217
.370

4 Latin Squares

Treatment

Comparison
Standard Error of Difference GLS CRD

.158

.159

.154

.159 
Figure 12

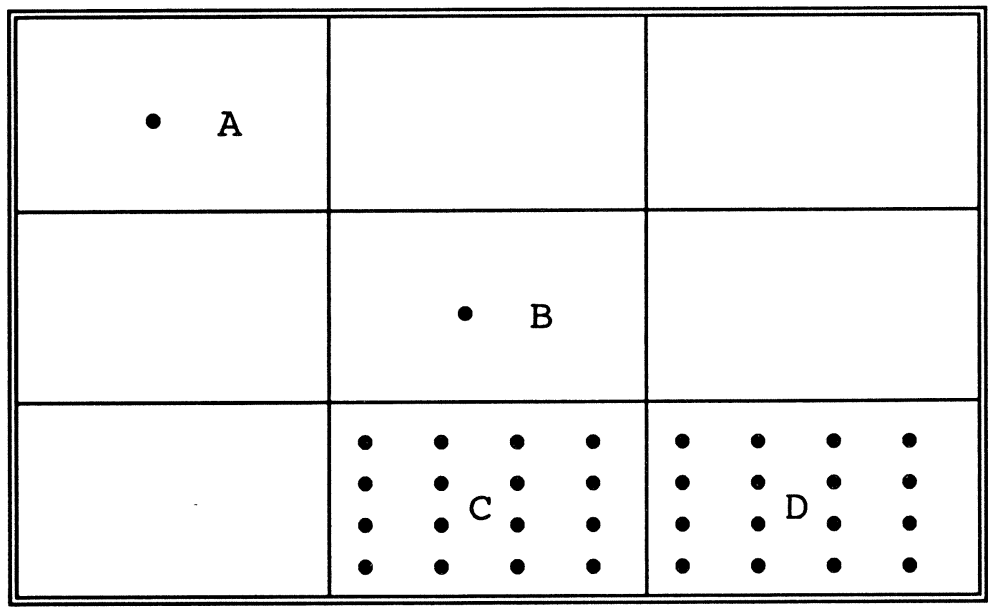

from plot $A$ to $B$ is not $\sqrt{ } 2$ but should be averaged over the area in both plots.

$\gamma(\mathrm{A}, \mathrm{B})=\iint_{\mathrm{A}} \iint_{\mathrm{B}} \gamma(\mathrm{h})$

This can be approximated by using a 4 by 4 grid overlaying each plot and then averaging the semivariogram values for the $16^{2}=256$ resulting points as seen in plots $C$ and $D$. 